\title{
Perilaku Remaja di Surabaya Barat dalam Pengobatan Jerawat
}

\author{
Stefani Nurhadi ${ }^{*}{ }^{*}$, Minarni Wartiningsih ${ }^{2}$ \\ Departemen Ilmu Kesehatan Kulit dan Kelamin, Fakultas Kedokteran \\ Universitas Ciputra, Citraland CBD Boulevard Surabaya ${ }^{1}$ \\ Departemen Ilmu Kesehatan Masyarakat, Fakultas Kedokteran Universitas \\ Ciputra, Citraland CBD Boulevard Surabaya ${ }^{2}$ \\ *e-mail: stefani.nurhadi@ciputra.ac.id
}

\begin{abstract}
Abstrak
Jerawat adalah kelainan kelenjar pilosebasea yang banyak diderita oleh remaja yang meskipun dapat sembuh sendiri tetapi dapat bekomplikasi skar permanen dan dampak psikologis. Oleh karena itu penting untuk meneliti perilaku remaja dalam mengatasi jerawatnya sehingga dapat diberikan edukasi yang sesuai sehingga komplikasi dapat dihindari. Tujuan penelitian ini adalah untuk mengetahui perilaku remaja di Surabaya Barat dalam pengobatan jerawat. Metode penelitian ini menggunakan desain analitik observasional dengan pendekatan cross sectional. Cara sampling yaitu cluster random sampling dengan variabel bebas yaitu perilaku remaja dalam pengobatan jerawat. Populasi adalah seluruh remaja yang berada di Surabaya Barat dengan besar sampel 251 responden. Instrumen yang digunakan adalah kuesioner. Variabel yang dinilai yaitu jenis kelamin, umur, kondisi jerawat, penyebab jerawat yang paling dicurigai, skor persepsi diri akibat jerawat, lamanya berjerawat, pengobatan jerawat, jenis pengobatan jerawat dan cara pengobatan jerawat oleh diri sendiri. Hasil penelitian didapatkan sebagian besar subyek penelitian mengobati jerawatnya 185 orang $(73.7 \%)$, namun hanya 45 orang $(24,3 \%)$ yang berkonsultasi ke dokter. Subyek yang mengobati jerawatnya sendiri terbanyak memakai produk anti jerawat non sabun yang dibeli di supermarket 76 orang $(36,7 \%)$, sering mencuci muka dilaporkan 55 orang $(21,9 \%)$, memencet jerawat sendiri dilaporkan 39 orang $(15,5 \%)$ dan memakai produk anti jerawat non sabun yang dibeli secara online dilaporkan 36 orang $(14,3 \%)$. Jenis kelamin, lamanya berjerawat dan tingkat pendidikan tidak berhubungan secara statistik dengan perilaku help seeking. Kesimpulannya perilaku help seeking remaja di Surabaya Barat dalam pengobatan jerawat cenderung memilih mengobati jerawatnya daripada berkonsultasi ke dokter. Subyek yang mengobati jerawatnya sendiri mayoritas menggunakan produk anti jerawat non sabun yang dibeli di supermarket. Serta tidak terdapat hubungan antara jenis kelamin, tingkat pendidikan dan lamanya berjerawat dengan perilaku help seeking pada remaja di Surabaya Barat.
\end{abstract}

Kata Kunci: jerawat, remaja, pengobatan

\section{Behaviour of Adolescents in West Surabaya in Treating Their Acne}

\begin{abstract}
Acne is a pilosebaceous gland disorder that affects many adolescents which can cause permanent scarring and psychological impact. Therefore is important to study adolescent behaviour in overcoming acne so that appropriate education can be given so complications can be avoided. The aim of this study was to determine the behaviour of adolescents in West Surabaya in treating acne. The study design was an observational analytic study using a cross
\end{abstract}


sectional approach. The population was all adolescents in West Surabaya with a sample size of 251 respondents taken by cluster random sampling. The results showed that the most of the study subjects did self medication was 185 people (73.7\%), but only 45 people (24.3\%) sought medical help. Most of the subjects who did self medication used over the counter (OTC) products purchased in supermarkets 76 people $(36,7 \%), 55$ people frequently washed their face $(21,9 \%)$, 39 people $(15,5 \%)$ popped their acne, 36 people $(14,3 \%)$ purchased OTC products online. While gender differences, duration of acne and level of education were not statistically related to help seeking behaviour. The conclusion is that the help seeking behaviour of teenagers in West Surabaya in treating acne tends to choose self medication rather than consulting a doctor. The majority of subjects who did self medication used OTC products bought in supermarkets. Furthermore, there are no relationship between gender, education level and duration of acne with help seeking behaviour among adolescents in West Surabaya.

Keywords: acne, adolescent, treatment, self medication

\section{PENDAHULUAN}

Usia remaja sering disertai banyak perubahan baik fisik maupun psikis yang disebabkan oleh perubahan hormonal. Perubahan dalam hal fisik tersebut antara lain adalah munculnya jerawat. Jerawat adalah kelainan kelenjar pilosebasea yang biasanya diderita oleh remaja dan dewasa muda. Biasanya muncul pada wajah, dada, punggung dan lengan atas (Goh et al., 2019). Menurut catatan dermatologi kosmetika Indonesia terdapat 60\% penderita jerawat pada tahun 2006, 80\% penderita pada tahun 2007 dan 90\% pada tahun 2009. Prevalensi tertinggi yaitu umur 14-17 tahun pada perempuan sekitar 8385\% dan pada laki-laki umur 16-19 tahun sekitar 95-100\% (Tjekyan, 2008).

Walaupun penyakit ini dapat sembuh dengan sendirinya, tetapi dapat terjadi akibat jangka panjang seperti terbentuknya skar permanen (Goh et al., 2019). Pada penelitian oleh Wahyuni (2007) di Jakarta dan Smithard et al. (2001) disimpulkan dampak jerawat signifikan pada kesehatan emosional dan tingkah laku pada usia remaja (Wahyuni, 2007; Smithard et al., 2001).

Ditambah lagi banyak iklan di media massa yang berlomba - lomba memperkenalkan produknya yang dapat menghilangkan jerawat dengan cepat dan ampuh. Selain itu maraknya kompetisi di media sosial seperti Instagram, Facebook maupun Youtube yang menampilkan remaja-remaja yang berkulit mulus dan bersih akan semakin mendorong remaja untuk meletakkan standar ideal penampilannya menurut apa yang mereka lihat (Rouner et al., 2003; Greenberg et al., 1992).

Dari penelitian Savo pada murid sekolah menengah di Albania, didapatkan $73.2 \%$ murid yang sedang/ pernah menderita jerawat melaporkan menerima 
ISSN 1978-2071 (Print); ISSN 2580-5967 (Online) Jurnal IImiah Kedokteran Wijaya Kusuma 10(2) : 131-141, September 2021

pengobatan, dan sisanya $26.8 \%$ tidak mengobati sama sekali. Diantara murid yang menerima pengobatan hanya $18.5 \%$ murid yang berobat ke dokter kulit, $37.8 \%$ menggunakan produk anti jerawat yang direkomendasikan teman, $16.9 \%$ menggunakan obat yang direkomendasikan oleh apotek (Savo et al., 2020). Sementara penelitian Alshehri et al menemukan perilaku mengobati sendiri dan penggunaan anti jerawat yang dibeli bebas umum dilakukan mahasiswa universitas di Arab Saudi. Produk bebas yang paling banyak digunakan adalah sabun cuci muka (Alshehri et al., 2017).

Dari studi terdahulu menyatakan berbagai cara akan remaja lakukan untuk menghilangkan jerawatnya, mulai dari mencoba mengobati sendiri hingga mencari pertolongan ke dokter. Penanganan jerawat yang tidak tepat maupun terlambat berobat ke dokter malah dapat memperparah jerawat bahkan dapat menimbulkan skar yang permanen. Oleh karena itu penelitian ini bertujuan untuk meneliti perilaku remaja di Surabaya dalam mengatasi jerawatnya sehingga dapat diberikan edukasi yang sesuai sehingga komplikasi berupa skar maupun gangguan psikologis dapat dihindari.

\section{BAHAN DAN METODE}

Metode penelitian ini menggunakan desain analitik observasional dengan pendekatan cross sectional. Populasi adalah seluruh remaja yang memiliki masalah jerawat dan berdomisili di Surabaya Barat. Sampel diperoleh dengan teknik cluster random sampling, dan besar sampel sejumlah 251 responden. Pengambilan sampel dilakukan berdasarkan pemilihan cluster dari 7 kecamatan, kemudian pengambilan sampel diambil pada 2 cluster terpilih secara acak, selanjutnya sampel diperoleh dari seluruh populasi dalam cluster tersebut. Instrumen yang digunakan adalah kuesioner. Analisis data dilakukan menggunakan SPSS, melalui Uji Chi Square dengan tingkat signifikan $\alpha=0,05$. Jika nilai $p<0,05$ berarti terdapat adanya hubungan antar variable.

\section{HASIL}

Karakteristik responden dalam penelitian ini dapat diamati berdasarkan jenis kelamin, umur, pendidikan terakhir, kondisi jerawat saat ini menurut subyek, lamanya berjerawat, dan cara pengobatan jerawat yang dilakukan. Total jumlah subyek adalah sebanyak 251 orang yang terdiri dari 125 (49,8\%) lelaki dan 126 $(50,2 \%)$ perempuan. Sedangkan distribusi usia terbanyak yaitu usia 19 tahun 49 subyek (19,5\%) diikuti dengan usia 20 tahun 43 subyek (17.13\%) dan 21 tahun 34 subyek (13.55\%). 
Perilaku Remaja di Surabaya Barat dalam Pengobatan Jerawat

Stefani Nurhadi, Minarni Wartiningsih

Kondisi jerawat saat ini terbanyak dilaporkan tergolong berat oleh 70 subyek $(27,9 \%)$ diikuti dengan sedang 60 subyek $(23,9 \%)$ dan hampir bersih 52 subyek $(20,7 \%)$. Sedangkan pemicu jerawat yang dicurigai oleh subyek paling banyak disebabkan oleh stress 133 orang (53\%), diikuti oleh menstruasi 64 subyek $(25,5 \%)$, serta makanan 26 orang (10.4\%).

Dalam hal persepsi diri, terbanyak 63 subyek (25.1\%) merasa kurang menarik akibat jerawatnya dengan skor 6, diikuti oleh 57 subyek (22.7\%) dengan skor 7 . Sementara itu, lamanya subyek berjerawat paling banyak 1-3 tahun yaitu 97 orang (38.6\%), selanjutnya 5 tahun 79 orang (32.5\%) dan $<1$ tahun 74 orang (29.5\%). Cara pengobatan jerawat yang dilakukan subyek dapat dilihat distribusinya pada Tabel 1.

Tabel 1. Cara pengobatan jerawat yang dilakukan

\begin{tabular}{cccc}
\hline $\begin{array}{c}\text { Pengobatan } \\
\text { jerawat }\end{array}$ & Frekuensi & $\begin{array}{c}\text { Jenis pengobatan } \\
\text { jerawat }\end{array}$ & Frekuensi \\
\hline Ya & $185(73,7 \%)$ & Ke Dokter & $45(17,9 \%)$ \\
Tidak & $66(26,3 \%)$ & Mengobati sendiri & $206(82,1 \%)$ \\
Total & $251(100 \%)$ & Total & $185(100 \%)$ \\
\hline
\end{tabular}

Sumber: Data Primer 2019

Tabel 1 dapat diketahui bahwa diantara semua subyek yang berjerawat, 185 subyek (73.7\%) mengobati jerawatnya dan 66 subyek (26.3\%) tidak mengobati jerawatnya. Diantara subyek yang mengobati jerawatnya terbanyak adalah subyek yang mengobati jerawatnya sendiri 206 subyek (82,1\%) sedangkan yang berkonsultasi ke dokter adalah 45 subyek $(17,9$ \%). Distribusi berbagai cara pengobatan jerawat oleh diri sendiri dapat dilihat pada Tabel 2.

Tabel 2. Cara pengobatan jerawat oleh diri sendiri

\begin{tabular}{lc}
\hline Cara pengobatan jerawat oleh diri sendiri & Frekuensi \\
\hline Memakai produk anti jerawat yang dibeli di supermarket & $76(36,7 \%)$ \\
Memakai produk anti jerawat yang dibeli secara online & $30(14,5 \%)$ \\
Memencet jerawat sendiri & $32(15,7 \%)$ \\
Sering mencuci muka & $46(22,2 \%)$ \\
Facial di Salon & $3(1,2 \%)$ \\
Lainnya & $20(9,7 \%)$ \\
Total & 206 \\
\hline
\end{tabular}

Sumber: Data Primer 2019

Pada Tabel 7 dapat dilihat subyek yang mengobati jerawatnya sendiri terbanyak memakai produk anti jerawat (non sabun) yang dibeli di supermarket 76 orang $(36,7 \%)$, sering mencuci muka dilaporkan 55 orang $(21,9 \%)$, memencet jerawat sendiri 
ISSN 1978-2071 (Print); ISSN 2580-5967 (Online) Jurnal IImiah Kedokteran Wijaya Kusuma 10(2) : 131-141, September 2021

dilaporkan 39 orang $(15,5 \%)$ dan memakai produk anti jerawat (non sabun) yang dibeli secara online dilaporkan 36 orang (14,3\%). Hubungan jenis kelamin dengan pengobatan jerawat dapat diamati dengan analisis data dengan chi square seperti yang dapat diamati pada Tabel 3.

Tabel 3. Hubungan antara variable jenis kelamin dan pengobatan jerawat

\begin{tabular}{cccc}
\hline $\begin{array}{c}\text { Jenis } \\
\text { kelamin }\end{array}$ & Mengobati jerawat & $\begin{array}{c}\text { Tidak mengobati } \\
\text { jerawat }\end{array}$ & Total \\
\hline Lelaki & 91 & 34 & 125 \\
Perempuan & 94 & 32 & 126 \\
Total & 185 & 66 & 251 \\
\hline
\end{tabular}

Keterangan: hasil uji Chi square dengan $p=0,746$ (Bermakna bila $P>0,05$ )

Hasil tabulasi silang pada tabel diatas dapat diketahui bahwa mayoritas lelaki dan perempuan mengobati jerawatnya yaitu 91 orang dan 94 orang. Perbedaan jenis kelamin ternyata tidak berhubungan dengan health seeking behaviour, dengan nilai $p=0.746(>0,05)$. Hubungan tingkat pendidikan dengan pengobatan jerawat dapat dilihat pada Tabel 4 .

Tabel 4. Hubungan antara variabel tingkat pendidikan dan pengobatan jerawat

\begin{tabular}{cccc}
\hline $\begin{array}{c}\text { Tingkat } \\
\begin{array}{c}\text { Pendidikan } \\
\text { terakhir }\end{array}\end{array}$ & Mengobati jerawat & $\begin{array}{c}\text { Tidak mengobati } \\
\text { jerawat }\end{array}$ & Total \\
\hline SMP & 45 & 23 & 68 \\
SMA & 119 & 35 & 154 \\
Sarjana & 21 & 8 & 29 \\
Total & 185 & 66 & 251 \\
\hline
\end{tabular}

Keterangan: hasil uji Chi square dengan $\mathrm{P}=0,220$ (Bermakna bila $\mathrm{P}>0,05$ )

Hasil tabulasi silang pada tabel diatas dapat

diketahui bahwa dari 251 responden

mayoritas yang mengobati jerawatnya

adalah subyek dengan tingkat pendidikan

terakhir SMA 119 orang. Hasil uji chi square tingkat pendidikan tidak ada hubungan dengan health seeking behaviour, dengan nilai $p=0.220$ (> 0.05). Hubungan lamanya berjerawat dengan pengobatan jerawat dapat diamati pada Tabel 5.

Tabel 5. Hubungan antara variabel lama berjerawat dan pengobatan jerawat

\begin{tabular}{cccc}
\hline $\begin{array}{c}\text { Lamanya } \\
\text { berjerawat }\end{array}$ & Mengobati jerawat & $\begin{array}{c}\text { Tidak mengobati } \\
\text { jerawat }\end{array}$ & Total \\
\hline Dibawah 1 tahun & 60 & 14 & 74 \\
1 sampai 3 tahun & 66 & 31 & 97 \\
3 sampai 5 tahun & 59 & 21 & 79 \\
Total & 185 & 66 & 251 \\
\hline
\end{tabular}

Keterangan: hasil uji Chi square dengan $\mathrm{p}=0,089$ (Bermakna bila $\mathrm{P}>0,05$ ) 
Dari tabel diatas dapat diketahui bahwa mayoritas yang mengobati jerawatnya telah berjerawat selama 1-3 tahun yaitu 66 orang. Dari hasil uji chi square lamanya subyek berjerawat tidak ada hubungan dengan health seeking behaviour, dengan nilai $\mathrm{p}=0.089(>0.05)$.

\section{PEMBAHASAN}

Hasil penelitian ini didapatkan kejadian jerawat paling banyak pada usia 19 tahun yaitu 49 subyek $(19,5 \%)$ diikuti dengan usia 20 tahun 43 subyek (17.13\%) dan 21 tahun 34 subyek (13.55\%). Hal ini sesuai dengan penelitian terdahulu oleh Nurhadi yang mengidentifikasi pasien jerawat di RSUP Sanglah Denpasar didapatkan terbanyak pada kelompok usia 15-24 tahun (Nurhadi S., 2018).

Jerawat adalah penyakit kulit yang terutama diderita remaja dan dewasa muda dengan prevalensi diperkirakan $85 \%$ pada usia 12-25 tahun. Sebenarnya jerawat dapat terjadi pada semua usia, dimulai saat neonatus (acne neonatal) dan bayi usia 1-12 bulan (acne infantile) dan remaja hingga dewasa. Namun kebanyakan pasien mulai berjerawat sekitar usia pubertas (Goh C. et al., 2019). Dari hasil penelitian jenis kelamin subyek penelitian hampir sama banyak antara laki-laki dan perempuan, terdiri dari 125 (49,8\%) subyek laki-laki dan 126 (50,2\%) subyek perempuan. Jerawat dapat diderita semua jenis kelamin namun laki-laki cenderung memiliki jerawat yang lebih berat, dan jerawat nodulokistik telah dilaporkan sering terjadi pada laki-laki kulit putih dibandingkan laki-laki kulit berwarna (Tan et al., 2015).

Hasil penelitian pada tabel 1 terdapat 185 subyek (73.7\%) yang mengobati jerawatnya dan 66 subyek (26.3\%) yang tidak mengobati jerawatnya. Diantara subyek yang mengobati jerawatnya 45 subyek $(24,3 \%)$ berobat ke dokter. Dari penelitian Savo pada murid sekolah menengah di Albania, didapatkan 73.2\% murid yang sedang/ pernah menderita jerawat melaporkan menerima pengobatan, dan sisanya $26.8 \%$ tidak mengobati sama sekali. Diantara murid yang menerima pengobatan hanya $18.5 \%$ murid yang berobat ke dokter kulit, 37.8\% menggunakan produk anti jerawat yang direkomendasikan teman, $16.9 \%$ menggunakan obat yang direkomendasikan oleh apotek (Savo et al., 2020). Hal ini menunjukkan bahwa terdapat kecenderungan remaja penderita jerawat yang mengobati jerawatnya lebih senang mencoba-coba produk terlebih dahulu daripada berkonsultasi ke dokter.

Hasil penelitian pada tabel 2 menunjukkan subyek yang mengobati jerawatnya sendiri terbanyak memakai produk anti jerawat non sabun yang dibeli 
di supermarket 76 orang $(36,7 \%)$, sering mencuci muka dilaporkan 55 orang $(21,9 \%)$, memencet jerawat sendiri dilaporkan 39 orang $(15,5 \%)$ dan memakai produk anti jerawat non sabun yang dibeli secara online dilaporkan 36 orang (14,3\%). Hal ini sesuai dengan penelitian Alshehri et al bahwa perilaku mengobati sendiri dan penggunaan anti jerawat yang dibeli bebas umum dilakukan mahasiswa universitas di Arab Saudi. Produk bebas yang paling banyak digunakan adalah sabun cuci muka (Alshehri et al., 2017). Namun belum banyak penelitian yang mempelajari sejauh mana produk bebas dapat mengobati jerawat sedang dan berat.

Mencuci muka merupakan hal mendasar dalam kesehatan dan higienitas personal. Mencuci muka bertujuan untuk menghilangkan kotoran, bakteri dan sel kulit mati. Pemilihan sabun yang benar penting untuk menjaga kesehatan kulit berjerawat. Sabun yang terbuat dari basa dan asam lemak dengan pH 9 hingga 10 dapat mengikis lapisan lemak pelindung kulit sehingga kulit menjadi kering. Karena kulit memiliki pH 5,3 sampai 5,9, mencuci kulit dengan sabun alkali akan meningkatkan $\mathrm{pH}$ 1,5 sampai 2 unit selama 4 sampai 8 jam. Peningkatan $\mathrm{pH}$ meningkatkan penguapan cairan melalui epidermis kulit, sehingga menyebabkan kulit tampak kering. Selain itu peningkatan
$\mathrm{pH}$ dapat mempermudah pertumbuhan mikroba sehingga meningkatkan pertumbuhan bakteri Propionibacterium acne dan munculnya lesi jerawat. Pembersih muka dengan deterjen sintetik memiliki pH sekitar 5,5 dan tidak mengubah pH kulit (Decker A et al., 2012). Sehingga pemilihan pembersih wajah yang benar dan cuci muka tidak berlebihan (2-3 kali sehari saja) penting dalam perawatan kulit berjerawat.

Pemencetan jerawat adalah hal yang sering dilakukan. Namun trauma fisik yang disebabkan pemencetan jerawat dapat menyebabkan peradangan dan menimbulkan kerusakan jaringan kulit. Pada suatu laporan kasus komedo terbuka yang diekstraksi dengan kuat, yang pastinya terasa nyeri bagi pasien, 24 jam kemudian dilakukan biopsy pada tempat yang sama dan didapatkan peradangan cukup berat dimana epitel komedo ruptur. Didapatkan abses di sekitar dan dalam komedo seukuran papul $(<0,5 \mathrm{~cm})$ dan perdarahan. Kasus lainnya berupa hasil pemeriksaan histopatologi dari kulit yang terdapat komedo tertutup yang diekstraksi 35 hari sebelumnya. Didapatkan saluran kelenjar pilosebasea yang tidak Kembali ke bentuk semula, namun tak beraturan sehingga keratinisasi tidak merata sehingga mempermudah sumbatan saluran kelenjar yang menyebabkan terbentuknya komedo. 
Ekstraksi manual komedo terbuka dan tertutup dengan komedo ekstraktor, sering kali masih meninggalkan inti komedo sehingga akan semakin cepat terbentuk komedo kembali (Plewig et al., 2019). Disini perlunya edukasi kepada masyarakat tentang perawatan jerawat yang dapat dilakukan sendiri dan yang sebaiknya tidak dilakukan agar jerawat tidak semakin parah dan menimbulkan komplikasi kerusakan kulit.

Hasil penelitian pada tabel 3 menunjukkan jenis kelamin ternyata tidak berhubungan dengan health seeking behaviour, dengan nilai $p=0.746(>0,05)$. Penelitian dari Savo et al. pada 2020 jenis kelamin perempuan lebih banyak mencari pertolongan untuk menyembuhkan jerawatnya (konsultasi dokter spesialis kulit, saran petugas apotek, saran teman) daripada jenis kelamin laki-laki dengan $p=0.001$ yang signifikan secara statistik. Sementara lebih banyak laki-laki (32.5\%) daripada perempuan (22.6\%) melaporkan tidak mengobati jerawatnya $(p=0.001)$ (Savo et al., 2020). Hal ini kemungkinan disebabkan kini tidak hanya perempuan, namun laki-laki pun juga memperhatikan penampilan. Hasil penelitian Chiu et al menunjukkan pengenalan sosial, ekspektasi sosial dan word-of-mouth, penampilan estetik, isu kesehatan dan keinginan membeli secara signifikan mempengaruhi laki-laki muda di China untuk membeli produk perawatan wajah (Chiu et al., 2018). Hasil penelitian pada tabel 4 menunjukkan variabel tingkat pendidikan tidak ada hubungan dengan health seeking behaviour, dengan nilai $\mathrm{p}=0.220(>0.05)$. Penelitian dari Savo et al. 2020, didapatkan murid yang berusia lebih dari 16 tahun lebih banyak berkonsultasi ke dokter spesialis kulit daripada murid yang lebih muda $(P=0.001)$. Responden berusia 14 sampai 15 tahun melaporkan sering bertanya ke petugas apotek atau tidak mengobati sama sekali dibandingkan teman-temannya yang lebih tua. Mereka yang tidak mengobati jerawatnya beralasan bahwa kesembuhan jerawat hanya sementara, tidak memiliki informasi dan merasa bingung bagaimana caranya ke dokter spesialis kulit, takut pengobatan tidak efektif dan biaya yang mahal (Savo et al., 2020). Hal ini juga sejalan dengan penelitian oleh Leelavathi et al. mengenai perilaku mencari pengobatan untuk jerawat diantara mahasiswa kedokteran dimana didapatkan 43,9\% $(n=108)$ mahasiswa kedokteran yang berjerawat membiarkan saja jerawatnya karena menganggap hal tersebut bukan masalah berarti (Leelavathi et al., 2015). Penelitian Desai et al. menemukan rendahnya health seeking behaviour pada remaja penderita jerawat 17 orang $(24,3 \%)$ pada kohort di fasilitas kesehatan dan 74 
ISSN 1978-2071 (Print); ISSN 2580-5967 (Online) Jurnal IImiah Kedokteran Wijaya Kusuma 10(2) : 131-141, September 2021

orang $(36,3 \%)$ saja yang menemui dokter pada kohort di masyarakat (Desai 2017).

Berdasarkan penelitian Desai terdapat beberapa alasan pasien berjerawat tidak mencari pertolongan untuk pengobatan jerawatnya. Pada individu berjerawat ringan 28 orang $(73,6 \%)$ percaya bahwa jerawatnya tidak cukup parah, 6 orang $(15,8 \%)$ merasa terlalu malu untukpergi ke dokter, 2 orang $(5,3 \%)$ mengatakan terlalu sibuk dan 2 orang $(5,3 \%)$ tidak menyebutkan alasan. Pada individu dengan jerawat sedang 6 orang $(54,5 \%)$ menyatakan terlalu malu untuk pergi ke dokter, 3 orang $(27,3 \%)$ merasa jerawatnya tidak terlalu parah dan 2 orang $(18,9 \%)$ terlalu sibuk. Sementara penderita jerawat berat 3 orang (75\%) menyatakan terlalu malu untuk bertemu dokter dan 1 orang $(25 \%)$ menyatakan jerawatnya tidak begitu parah (Desai 2017). Penelitian Savo pada subyek yang tidak mengobati jerawatnya ke dokter karena alasan efek terapi hanya sementara (27\%), kurang informasi dan merasa bingung bagaimana mendapatkan dokter kulit (14\%) dan obat anti jerawat tidak efektif (10.5\%) dan takut biaya mahal (7.4\%) (Savo et al.,2020). Keterlambatan pengobatan jerawat dapat menyebabkan jerawat terlanjur parah sehingga menyulitkan pengobatan maupun berkomplikasi timbulnya skar permanen dan gangguan psikologis. Oleh karena itu, diperlukan adanya penyuluhan kepada masyarakat kapan perlu mencari pertolongan dokter untuk masalah jerawatnya.

Hasil penelitian pada tabel 10 menunjukkan bahwa lamanya subyek berjerawat tidak ada hubungan dengan health seeking behaviour, dengan nilai $p=0.089$ (> 0.05). Kemungkinan hal ini disebabkan oleh persepsi seseorang terhadap penampilannya sangat subyektif sehingga lamanya berjerawat tidak selalu membuat orang ingin mengobati jerawatnya. Sosialisasi mengenai pentingnya pengobatan jerawat dapat membantu pasien mendapatkan wajah bersih lebih cepat dan terhindar dari komplikasi skar bekas jerawat yang sulit pengobatannya dan memakan biaya lebih besar. Wajah yang bersih dan penampilan menarik tentunya akan membuat orang lebih percaya diri dan lebih banyak peluang dalam hal karir maupun mencari pasangan. Keterbatasan penelitian ini adalah tidak menilai tingkat ekonomi dari subyek penelitian sehingga perilaku health seeking dapat bervariasi dipengaruhi oleh tingkat ekonomi individu. Selain itu karena keterbatasan sumber daya dan waktu, kami hanya mengambil sampel dari wilayah Surabaya Barat. 


\section{KESIMPULAN}

Berdasarkan hasil penelitian dan pembahasan yang telah diuraikan maka dapat dibuat kesimpulan bahwa sebagian besar subyek penelitian lebih memilih mengobati jerawatnya daripada berkonsultasi ke dokter. Subyek yang mengobati jerawatnya sendiri mayoritas menggunakan produk anti jerawat non sabun yang dibeli di supermarket. Sedangkan berdasarkan analisis statistik chi square didapatkan tidak terdapat hubungan antara jenis kelamin, tingkat pendidikan dan lamanya berjerawat dengan perilaku help seeking pada remaja di Surabaya Barat.

\section{SARAN}

Mengingat jerawat adalah penyakit kulit yang paling banyak diderita remaja dan dapat menimbulkan skar permanen maupun dampak psikologis yang signifikan maka Dokter, orang tua dan guru perlu mengenali remaja yang berjerawat. Sehingga penyuluhan mengenai perawatan kulit yang benar dan pemilihan produk perawatan kulit untuk kulit berjerawat perlu dilakukan. Sekolah perlu mengadakan seminar tentang jerawat agar remaja mengetahui bahwa jerawat dapat diobati dan bilamana perlu berkonsultasi ke dokter. Diperlukan lebih banyak penelitian mengenai sejauh mana produk yang dapat di beli bebas (di supermarket maupun toko online) dapat membantu kesembuhan jerawat sedang dan berat.

\section{DAFTAR PUSTAKA}

Alshehri MD, Almutairi AT, Alomran AM, Alrashed BA, Kalidayan F. 2017. Over the counter and prescription medication for acne: a cross sectional survey in a sample of university students in Saudi Arabia. Indian Dermatol Online J. $8(2): 120-123$.

Chiu CL, Wang Q, Ho H-C, Zhang J, Zhao F. 2018. Metrosexual trend in facial care products: Analysis of factors that influence young Chinese men purchasing intention. https://doi.org/10.1080/20932685.20 $\underline{19.1639527}$

Decker A., Grabber EM. Over the counter acne treatments A Review.2012. J Clin Aesthet Dermatol. 5(5):32-40. Desai KP, Martyn-Simmons C, Viner R, Segal T. 2017. Help-seeking behaviours, opportunistic treatment and psychological implications of adolescent acne: cross-sectional studies in schools and hospital outpatient departments in UK. BMJ Open. 7:e016964.

Goh C, Cheng C, Agak G, Zaenglein AL, Graber EM, Thiboutot DM, Kim J. 2019. Acne Vulgaris. Editor: Kang 
S., Amagai M., Bruckner A.L., Enk A.H., Margolis D.J., McMichael A.J., Orringer J.S. Fitzpatrick's Dermatology. $9^{\text {th }}$ Ed. Vol 1. New York: Mc Graw Hill. P 1391-1418.

Leelavathi M, Tan HC, Puah JWD, Apipi M, Sohami AE, Mahat NF. 2015. Acne disability, self management and help seeking behaviour among medical students. Med \& Health. 10(1):1-9.

Plewig G, Melnik B, Chen WC. 2019. Plewig and Kligman's Acne and Rosacea $4^{\text {th }}$ Ed. Switzerland: Springer. P.282-4.

Rouner D, Slater MD, Domenech-Rodriguez, M. 2003. Adolescent Evaluation of Gender Role and Sexual Imaginary in Television Advertisements. Journal of Broadcasting and Electronic Media. 47(3);435-54.

Savo I, Jongaqi E, Vasilli E, Mishtaku S, Demaj D, Jafferany M. 2020. Treatment-seeking behaviour, knowledge and beliefs about acne vulgaris among adolescents: A cross-sectional study in high school students in Tirana, Albania. Dermatologic Therapy. e13500.

Smithard A, Glazebrook C, Williams HC. 2001. Acne Prevalence, Knowledge About Acne and Psychological morbidity in MidAdolescence: A Community-Based Study. British Journal of Dermatology. 145(2).

Tan JK, Bhate K. 2015. A Global perspective on the epidemiology of acne. $\mathrm{Br} J$ Dermatol. 172(suppl 1):3-12.

Tjekyan RM. 2008. Kejadian dan Faktor Risiko Jerawat. Jurnal media medika indonesiana. 43(1):6-12.

Wahyuni E. 2007. Hubungan Persepsi Tentang jerawat Dengan Kepercayaan diri Remaja Akhir [skripsi]. Jakarta: Fakultas Psikologi Universitas Islam Negri Syarif Hidayatullah Jakarta. 2007; 1-66. 